anos depois. Os padrões dos comportamentos das crianças aos 4 anos, relacionados com a alimentação e a saúde oral, permaneceram aos 7 anos. Conclusões: As estratégias preventivas elencadas para a idade pediátrica devem incidir sobretudo nos hábitos alimentares e nas suas características de consumo. Para a promoção da saúde oral infantil é necessário consciencializar os responsáveis para a importância da constituição dos lanches, assim como, nas principais refeições evitar o elevado consumo de alimentos pobres em micronutrientes com elevada densidade em energia, por exemplo, as bebidas adoçadas com açúcar.

http://doi.org/10.24873/j.rpemd.2022.01.912

\#056 Prevalência de sinais clínicos de parafunções nos dentes anteriores

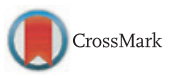

Helena Salgado*, Pedro Martins, Vanessa Silva, Patrícia Fonseca

Universidade Católica Portuguesa, Faculdade de Medicina Dentária

Objetivos: Identificar a presença de desgastes dentários e fissuras de esmalte/dentina nos dentes anteriores. Estabelecer a relação causal entre os sinais clínicos mencionados e a presença de hábitos parafuncionais. Materiais e métodos: Estudo observacional transversal, clínico e sem intervenção com base na população de pacientes que frequenta a Clínica Dentária Universitária da FMD-UCP. Foram incluídos no estudo: indivíduos com 15 ou mais anos de idade; colaborantes; com suporte posterior constituído por dentes naturais ou protéticos; portadores de pelo menos 4 dentes anteriores em cada arcada, sendo que os dentes perdidos não podiam ser caninos. A amostra foi constituída por 103 indivíduos, aos quais foi realizado um exame clínico pelo investigador principal e aplicado um questionário do tipo autoaplicativo. Analisou-se cada um dos dentes anteriores presentes na cavidade oral tendo-se determinado o desgaste dentário segundo a classificação de Smith \% 26 Knight e detetada a presença de fissuras ou craze lines na face vestibular de cada dente, sendo estas caraterizadas de acordo com o seu posicionamento principal em relação aos terços dentários e com a orientação que seguiam. Resultados: Dos hábitos parafuncionais avaliados através do questionário os mais prevalentes foram a utilização de pastilha elástica e o apoio do queixo com a mão. Os caninos na arcada superior e os incisivos centrais na arcada inferior foram os dentes mais afetados por desgaste. Os incisivos centrais superiores foram os dentes que apresentaram maior número de fissuras. $\mathrm{Na}$ maior parte dos casos as fissuras atingiam o terço incisal e apresentava uma orientação vertical. Todos os dentes com exceção dos caninos superiores evidenciaram um maior nível de desgaste em indivíduos com idades mais avançadas. Verificou-se uma correlação positiva moderada entre a variável mastigação unilateral e o desgaste no incisivo central inferior esquerdo. Foi encontrada uma correlação positiva forte entre o número de fissuras e a orientação por estas seguida, sendo que nos dentes com maior número de fissuras, as mesmas seguiam maio- ritariamente uma direção vertical. Conclusões: Verificaram-se algumas relações entre os hábitos parafuncionais e os sinais clínicos evidenciados pelos dentes anteriores, pelo que se conclui que o diagnóstico precoce de parafunções é de extrema importância para prevenir o aparecimento de desgaste e fissuras nesses dentes.

http://doi.org/10.24873/j.rpemd.2022.01.913

\section{\#057 Efeito de distintos métodos de remoção do compósito no esmalte após descolagem de brackets}

Francisca Aguiar*, Carolina Pereira, Laura Ferreira, Ana Catarina Silva, Teresa Oliveira, Paulo Melo

FMDUP - EPIUnit - ISPUP - ITR

Objetivos: Identificar, através de uma revisão sistemática, o(s) método(s) de remoção do compósito residual após a descolagem dos brackets ortodônticos que produz(em) o menor dano iatrogénico na superfície do esmalte. Materiais e métodos: Foi efetuada uma pesquisa bibliográfica nas bases de dados MEDLINE/PubMed, SCOPUS e Web of Science, recorrendo às seguintes palavras-chave: orthodontics; bracket; debonding; debracketing; adhesive; composite; residual; remnants; removal; clean-up e enamel. Foram selecionados artigos publicados entre janeiro de 2010 e dezembro de 2020, que avaliam e comparam os efeitos de diferentes métodos de remoção do compósito residual no esmalte humano sem defeitos, após a descolagem dos brackets metálicos, no que diz respeito, ao dano e à rugosidade superficial produzidos. Resultados: De um total de 371 artigos, foram incluídos 20 neste trabalho, 19 com investigações in vitro e 1 in vivo, classificados como quantitativos ou qualitativos, dependendo do modo de avaliação da superfície do esmalte após a remoção do compósito residual. As brocas de carboneto de tungsténio promoveram alterações qualitativas variáveis na superfície do esmalte. Seis estudos observaram um aumento significativo $(p<0,05)$ na rugosidade superficial. A diminuição na rugosidade superficial encontrada em 4 estudos, parece resultar de uma perda substancial na espessura do esmalte, em média 7,9um. A remoção do compósito residual com pedras de Arkansas, brocas diamantadas de acabamento, pontas de ultrassom ou LASER Er: YAG produziu superfícies significativamente $(\mathrm{p}<0,05)$ mais rugosas e com danos. O uso do alicate para a remoção do compósito aumentou, de forma não significativa, a rugosidade superficial e, microscopicamente, as superfícies de esmalte apresentavam danos, apesar de serem consideradas superfícies aceitáveis. Microscopicamente, as brocas de compósito, os discos abrasivos e as brocas de polimento à base de óxido de alumínio apresentaram uma maior probabilidade de produzirem superfícies de esmalte lisas, homogéneas e com uma topografia muito próxima à das superfícies de esmalte iniciais e intactas. Conclusões: A utilização de brocas de carboneto de tungsténio, seguida de brocas de compósito, discos abrasivos ou brocas de polimento à base de óxido de alumínio, parece ser o método de remoção do compósito residual após a descolagem dos brackets ortodônticos que produz o menor 